\title{
A Reinterpretation of Confucian Philosophy of Education
}

\author{
Xia Yu' ${ }^{1,2}$ \\ ${ }^{1}$ School of Foreign Languages, Southwest University of Political Science and Law, Chongqing, China \\ ${ }^{2}$ Southwest University, Chongqing, China \\ Email: Sheilayu327@hotmail.com
}

How to cite this paper: Yu, X. (2017) A Reinterpretation of Confucian Philosophy of Education. Open Journal of Social Sciences, 5, 244-253.

https://doi.org/10.4236/jss.2017.57015

Received: June 3, 2017

Accepted: July 16, 2017

Published: July 19, 2017

Copyright $\odot 2017$ by author and Scientific Research Publishing Inc. This work is licensed under the Creative Commons Attribution International License (CC BY 4.0).

http://creativecommons.org/licenses/by/4.0/

\begin{abstract}
Confucius' theory of learning is more often than not understood in the West as one which emphasises learning through rote-memorisation and the mastery of essential knowledge as well as behavioural norms preserved in the culture of antiquity, therefore devoid of critical thinking. Drawing on Freire and Dewey's education theories, this paper re-examines Confucian conception of learning, revealing the coexistence of emphasis on critical thinking as well as memorisation of existing knowledge. We have thus argued that the Confucian philosophy of education is relevant even in the twenty-first century as enquiring and questioning are considered central to the quest for knowledge in Confucian learning.
\end{abstract}

\section{Keywords}

Confucian Philosophy, Education, Memorization, Critical Thinking

\section{Introduction}

Condemnation of memorization has become a salient feature in the most progressive theories in contemporary education [1]. Any educational theories acknowledging or highlighting the role of memorization (Confucius' theory of learning, for instance) are regarded as irrelevant to modern situations. This position seems to have stemmed from the following assumptions: 1) Learning through memorization does not lead to knowledge or wisdom; 2) Memorization is intrinsically incompatible with critical thinking, which is an integral component of modern education. My proceeding discussion will be on examining these conjectures.

\subsection{Is Memorization Legitimate in Learning?}

In attacking narrative education ${ }^{1}$, Paolo Freire, the radical Latin American edu-

${ }^{1}$ By "narrative", Freire means that in traditional education, the teacher-student relationship at any level reveals its fundamentally narrative character, which involves a narrating Subject (the teacher) and patient, listening Objects (the students). 
cation theorist (1921-1997) made the following statement:

Instead of communicating, the teacher issues communiqués and makes deposits which the students patiently receive, memorise, and repeat. This is the "banking" concept of education, in which the scope of action allowed to the students extends only as far as receiving, filing, and storing the deposits $[2]$.

Although memorization was not exceptionally singled out here, the connotation of memorization is negative:

Narration (with the teacher as narrator) leads the students to memorise mechanically the narrated content. Worse yet, it turns them into "containers", into "receptacles" to be filled by the teacher [2].

The banking model of education fails in the eyes of Freire because men are "filed away through the lack of knowledge in this misguided system" [2]. In other words, memorization of the "narrated content" does not lead to any knowledge. The most fundamental problem with this model, according to Freire, seems to be the misunderstanding of knowledge. For him, knowledge can never be obtained through transmission or memorization, "knowledge emerges only through invention and reinvention, through the restless, impatient, continuing, hopeful inquiry". For many kinds of important knowledge, Freire is certainly correct, however, I concur with Kim [1], who points out that not all the things we know are known only after and because of critical inquiry and the active transformation of data. For example, "Four times four is sixteen; the capital of Para is Belem" [2]. This established knowledge or even fact (as I call it), apparently requires no such process of critical inquiry as Freire describes. At least, the type of knowledge like "the capital of Para is Belem" requires little active engagement on the part of the learner compared to knowing "why or how Belem becomes the capital of Para".

This sort of "mundane knowledge", as Kim [1] call it, is vividly referred to in Chinese as "si zhi shi" [this literally means "dead knowledge"- "inflexible knowledge" would be a better translation]. Negative though it may appear, the word "dead" here has nothing to do with being obsolete or outdated, but simply conveys the notion that there is almost no chance for us to challenge the truthfulness or correctness of this knowledge ${ }^{2}$ (unless the capital of Para is changed later). Recognition of the significance of critical inquiry should not lead us to go the extreme to deny the existence of "dead" knowledge simply because it is as basic as common sense or because it involves no reasoning or leaves little room for critique on the part of the learner. Although I strongly reject the idea that learning is the mere banking or storing of information or opinion, I also refuse to accept that memorising the essence of the antiquity or scientific basics which ${ }^{2}$ This may partly explain why memorisation is used as the most effective and efficient way to deal with this sort of knowledge in Chinese culture of learning. Memorisation, or let us assume it is what some people call "rote-learning" - "si ji yin bei" [literally means "dead and inflexible memorization"] in Chinese, may be considered a suitable way to learn "dead" knowledge: it seems logical to learn inflexible knowledge using an inflexible method. 
have been attested through thousands of years of human experiences does not constitute learning or lead to knowledge or wisdom. I am not oblivious of Dewey's notion of two senses of the word "learning":

On the one hand learning is the sum total of what is known, as that is handed down by books and learned men. It is something external, an accumulation of cognitions as one might store material commodities in a warehouse. Truth exists ready-made somewhere. Study is then the process by which an individual draws on what is in storage. On the other hand, learning means something which the individual does when he studies. ... [3].

It has thus been conceived that accumulation and storage of what is transmitted from "books and learned men" does constitute part of learning inasmuch as truth can exist in a "ready-made" form. Viewed in this light, memorization and retention of the ready-made "body of truth" is not only legitimate in but an indispensable component of learning. To quote Thompson, "It is difficult to think of any educational goal for which the ability to retain information is unimportant. Human memory is crucial to the concept of learning" [4].

\subsection{Is Memorization Doomed to Be Incompatible with Critical Thinking?}

The rejection of memorization in learning for some critical thinking theorists represented by Freire [1] [5] [6] [7] might have originated from the presumption that memorization is doomed to be counteractive or detrimental to critical thinking. Given the near unanimity of contemporary acceptance of the importance of critical thinking, memorization seems to be an element which should be minimised or even eliminated in learning.

Prior to proceeding further, I have to add two caveats in understanding Freire's education philosophy. First, the Freirean method might be much more concerned with human need, namely the development of a just society than with education per se [8]. The Freirean sense of education has always been intertwined with freedom and understood as a means of "freeing people from the bondage of the culture of silence" [9]. If the Pedagogy of the Oppressed should not be read as a "revolutionary pedagogy" but as a "pedagogy for revolution" [10], caution may need to be taken in assessing its relevance to modern education or transferability to the context where the efficacy of education is a more central matter than liberating the oppressed. Second, Freire [2] starkly contrasts two forms of education: Banking-Digestive Education vs. Dialogue-Liberating Education. If we simply accept Freire's [2] dichotomy, the temptation, according to Taylor, is that "we attempt to combat banking education by creating a new model from those elements which lie on the opposing poles" [8]. In doing so, we arrive logically at the concept of "education for freedom", it remains, however, a question "whether, ontologically, this new, proposed polarity can actually exist" [8].

An implicit argument in Freire's education theory appears to be that the soli- 
tary goal of memorization is to blindly repeat other's views like a parrot, which is in principle incompatible with, or banishes critical thinking. He states, "The more students work at storing the deposits entrusted to them, the less they develop the critical consciousness ...". What is alluded to here more than anything else is that, the more one stores the "deposits", the less critical one would become. While this view is not without its rationality in the sense that the knowledge one already knows may, under certain circumstances, constrain the scope of one's imagination, it is obviously an exaggeration in most cases. The problem with the argument is that the learning process is likened to a closed space in which memorization of knowledge and critical consciousness are competing with each for the occupation of a limited area. If memorised knowledge is allowed more space, less room would be left for critical consciousness. Does the augmentation of memorised knowledge necessarily impede or inhibit the development of critical consciousness?

To address this question, we need first to develop an understanding of the role of the accumulation of existing knowledge. It is not only that knowledge can be ready-made either from books or learned men, but also according to Dewey [3], this knowledge "furnishes the means of understanding or giving meaning to what is still going on and what is to be done". Taking the example of a physician, Dewey notes, "what he [physician] has found out by personal acquaintance and by study of what others have ascertained and recorded" is knowledge to him because

It supplies the resources by which he interprets the unknown things which confront him, fills out the partial obvious facts with connected suggested phenomena, foresees their probable future, and makes plans accordingly $[3]$.

In this view, knowledge learned through mastery of past experience or others' opinions to achieve an acquaintanceship with existing information serves to lay a foundation or forge a source on which more creative work can build.

Dewey [3] continues to argue that men could not "really throw away all transmitted beliefs concerning the realities of existence, and start afresh upon the basis of their private, exclusive sensations and ideas", because the only outcome of doing so would be "general imbecility". Instead, human history is the one of revision and reorganisation of beliefs:

Men set out from what had passed as knowledge, and critically investigated the grounds upon which it rested; they noted exceptions; they used new mechanical appliances to bring to light data inconsistent with what had been believed; they used their imaginations to conceive a world different from that in which their forefathers had put their trust [3].

Thus viewed, knowledge that is passed or transmitted can serve as a starting point for critical investigation. It is this transmitted knowledge that lays the ground for people to examine its hidden assumptions and arguments, so as to detect and correct any inconsistency in the old knowledge. 
Adopting an open-ended perspective on the learning process, Dewey sees the acquisition of existing knowledge as a facilitation rather than impairment to the configuration of "what is to be done", or, in Freire's [2] words, "a task of re-creating that knowledge". It seems that memorising transmitted knowledge and the development of creative consciousness do not necessarily pose an eitheror choice, as is indicated by Freire's theory; it would be more rational to view these two as virtuously complementary to each other.

One may argue that, however, acquisition of existing knowledge may not be the same thing as the memorization of this knowledge. The issue of the approach to knowledge naturally arises. Rejecting the notion that bodies of knowledge were self-contained entities, Dewey insists that an approach to knowledge has to be rooted in the concept of the social origin of learning in order to "avoid the pitfalls of isolated abstraction" [11]. If Dewey's theory of knowledge and learning was rooted in the reality of the human situation or experience, the Confucian approach to knowledge is not categorically different in this sense insomuch as Confucius does not value learning or inquiry that is not anchored in and responsive to the lived daily experience of men. What is distinctive to the Confucian tradition of education might be that memorization is seen as one possibleperhaps significant-means of attaining knowledge. Although some educationalists may take the view that memorization is not the best way to acquire a knowledge store, it might be a pragmatic or efficient way for Chinese learners to establish information in their mind. While contemporary education in China is still being criticised for focusing on the acquisition of a vast store of knowledge at the expense of creativity, this is not to deny that this mode of education does enable the students to lay a solid foundation in knowledge accumulation.

\section{Is Confucius' Theory of Learning Relevant Today?}

Confucius' theory of learning is generally understood in the West as one which emphasises learning through rote-memorisation and the mastery of essential knowledge as well as behavioural norms preserved in the culture of antiquity [1]. It is assumed by Western scholars that the Confucian definition of knowledge is as something which can be directly "taken out [from the book] and put inside the students' heads" [12]. It is also supposed that Confucius takes learning as a process of blind accumulation, memorisation and retention of beliefs in the classics, which is identical with the "banking" concept of education. Is Confucius truly an advocate of a banking model of education? Or in other words, is Confucius' conception of learning at odds with critical thinking?

Recent studies of Chinese philosophy lead to increasing recognition of the rationality of many ancient thinkers represented by Confucius. Graham [13], an influential commentator, even regards Confucius as himself a rational, critical thinker. However, he still holds that Confucius' conception of learning places very a low premium on thinking when compared to learning. Such an interpretation is really unfair for Confucius as he explicitly states in The Analects. "He who just studies but does not think will be puzzled. He who just thinks but does 
not study will be perilous." This quotation shows that Confucius takes thinking as important as learning ${ }^{3}$, and views them as a two-part integrated system the lack of either of which would be dangerous. For him, learning cannot be separated from thinking: only learning with thinking or thinking with learning can be counted as the full sense of learning that Confucius is intending to promote. This is demonstrated in the following episode:

Si, you think of me as one who studies many things and remembers them, don't you?

He replied: Yes, is it not the case?

He said: It is not. There is one thing I use to string them together [14].

Clearly, Confucius does not limit his learning to memorisation or "filling the deposits". "Study[ing] many things and remember[ing] them" is one of the two means for the accumulation of raw materials of knowledge, out of which wisdom is constructed or extracted. There is "one thing" in addition that he uses as a tool to transform the raw material into wisdom or knowledge in the full Confucian sense, and that distinguishes himself from the rote-learner and the blind accumulator of knowledge. Needless to say, the "one thing" required to string together the many things that he studies and remembers is thinking, or, to be specific, synthesis, systemisation and integration of raw materials. In essence, what Confucius meant, in C. Chang's [15] understanding, was that knowledge is based on both data and method of thinking:

If one has no data to work with, and merely plays with the phantasms of one's imagination, thought will be unreliable or adventurous. If one collects many data, scattered, piecemeal, and unrelated, no principle will run like a thread through the congeries to organise them into a system [15].

Thus, Confucian thought on education is by no means a Chinese version of the "banking concept of education" [2], meaning only that the students are supposed to receive, memorise, and repeat what is deposited in the classics without understanding or active engagement.

A fundamental problem with the banking model of education, according to Freire, is that it misunderstands knowledge itself. The Freirean sense of knowledge "emerges only through invention and reinvention, through restless, impatient, continuing, hopeful inquiry" [6]. For him, the banking model fails because it precludes such invention, reinvention and inquiry. An important question to ask is what Confucius had in mind when he thought of "knowledge". Confucius states,

Surely there are people who achieve something without knowledge, but I for my part lack this characteristic. To hear much and select the good points from it and copy them, to see much and remember it constitutes an inferior variety of knowledge [14].

${ }^{3}$ Learning here can be understood as the more mundane sense of the term, the "memorising basic arithmetical facts" sense of the term-seeing, hearing, and remembering, amassing data [1]. That's why learning is contrasted with thinking in the quotation. 
Clearly, although the importance of seeing, hearing and remembering the wisdom of others is acknowledged, what one hears, sees and memorises makes only an "inferior variety of knowledge". This is because the acquisition of important facts through experience, through listening to others and observing them is not sufficient. This style of learning deprived of thinking is, as mentioned earlier, considered by Confucius hazardous and not leading to the full Confucian sense of knowledge. The facts one memorises through hearing and seeing, though passing for knowledge, constitute only the raw material out of which superior knowledge or wisdom is constructed. Obviously, there is something that is needed to make the raw material wisdom or a superior kind of knowledge.

Critical thinking theorists, nevertheless, may argue that thinking in a Confucian sense is not equivalent to the critical thinking they refer to. A Confucian version of critical thinking might better be defined as "rationally reflective thinking which is concerned with what to do or believe" [1]. I call this a weak form of critical thinking as opposed to Freire's strong form. In contrast with active transformation of raw material on the part of the learners (in order to prepare them to become "transformers of that world" [6], Confucius' reflective thinking "presupposes and reinforces the learners" examining underlying principles, being open-minded in listening and considering the views of others, being fair-minded in balancing and assessing evidence, and thinking autonomously in judging and assuming responsibility for one's beliefs' [1]. Such reflective thinking includes (1) reflection on the materials of knowledge in order to synthesise and systemise the raw materials into a whole, and to integrate them into oneself as wisdom; and (2) reflection on oneself in order to ensure that such synthesis, systemisation, and integration proceed in an open-minded, fair and autonomous way. To elaborate on this would be off the track of the present discussion, but it needs to be pointed out that these reflections are indeed one of the basic features of "problem-posing education" which, in Freire's [2] words, "bases itself on creativity and stimulates true reflection and action upon reality".

That Confucius has been seen as a believer in the banking model of education may be related to his claim that "[B] eing fond of the truth, I am an admirer of antiquity" (The Analects, 7.1) [14]. What Confucius means is that truth-what we today would call wisdom-was attained in antiquity and that his task in learning and teaching is to make sure truth of such a kind is not lost. Although he made no active effort to transform the content of what he considers true knowledge, Confucius does emphasise the need for active engagement on the part of learners in the form of analysing, reconstructing, synthesising and evaluating what is transmitted. For Confucius, fully mastering or internalising traditional propriety (out of admiration for antiquity) not only does not preclude but also requires the learner's active engagement, and conceptualising learning as storing and transmitting does not necessarily rule out critical thinking, even if wisdom is one and the same for both the ancients and the moderns. In essence, Confucius' "admiration of antiquity" is more a result of constructive criticism 
and honest evaluation than blind worship for, he declares, "I am the one who through my admiration of antiquity is keen to discover things". Confucius' admiration of antiquity and stress on the memorisation of the wisdom of ancestors do not prevent him from attaching value to critical thinking, which is evident from the following quote: "[A gentleman should] study extensively, inquire prudently, think carefully, distinguish clearly ...." [16] Evidently, extensive study and intentional memorisation is only one aspect of what Confucius has in his mind for learning, and an equally, if not more, important part is inquiry. He even talked about how thinking should be carried out: “...asks sincerely and thinks about what is at hand and then expands ...." [... qie wen er jin si ....] [17].

It thus appears that critical thinking is not only allowed but emphasised in a Confucian view of learning. Different from the banking model of education where "the students are not called upon to know, but to memorise the contents narrated by the teacher" [2], a Confucian version of education insists that the students truly "know" the content through their meaningful cognitive involvement prior to memorisation of the content. Instead of advocating accumulating or memorising uncritically and therefore ending up becoming what Freire [2] calls "collectors or cataloguers of things they store", Confucius encourages critical thinking through active engagement in open-minded self-reflection or responding to the wisdom of antiquity and the lived daily experience of men. In fact, Confucian education places a great emphasis on the balance "between book knowledge and the capacity to act and think independently" [18]. Interesting evidence may be found in the Chinese term (xuewen) for "knowledge" which is made up of two characters: One is xue (to learn) and the other is "wen" (to ask). This implies that the action of enquiring and questioning is central to the quest for knowledge.

What is pivotal to the understanding of Confucian learning philosophy, it has to be pointed out, is that one must be deeply steeped in the material through successive repetitions, iterations and memorisation, each of which drills deeper and deeper in to the grasp of the meaning before one wins the right to depart from the material. Learners from Confucian heritage are by no means dissenters from critical thinking; they simply cast doubt on the possibility of questioning or challenging when one does not command considerable basics and profound comprehension of a given topic, especially in the early stages of learning. A fundamental question which puzzles them might be: how can understanding result from free-for-all questioning rooted in ignorance, while Westerners are wondering how memorisation does not hamper creative thinking.

\section{Conclusion}

Confucian learning is not merely the uncritical rote memorisation of whatever is in the textbook as stereotypically understood by westerners. The Confucian sense of memorisation is far from being "an easy cop-out or a release from thinking" [19] for, as Lee [20] interprets, "the purpose of [Confucian] learning is to cultivate oneself as an intelligent, creative, independent, autonomous being". 
On the contrary, Confucius' thought on education rejects the banking education which "anesthetizes and inhibits creative power" [2]. Therefore, Confucius' learning theory does not preclude critical thinking and can be of high relevance to education today. Traditional wisdom can be useful in tackling modern problems if we take a balanced attitude towards them, as is conveyed in a Chinese idiom-“Qu qi zaopo, qu qi jinghua” [meaning "discarding the dross, selecting the essence"]. What goes wrong with Confucian education may be more concerned with the fact that traditional and classical texts may be made an unchallengeable authority for learners to treasure up (which is not to deny that many of the values conveyed by ancient classics have been respected for centuries in Chinese society even up to today as they deserve) than the way it engages learners in learning. Confucian emphasis on the importance of transmission of values (especially those which have withstood the test of time and human experiences) may give a new momentum to the establishment of a comprehensive education system and make Confucianism a living tradition for the twenty-first century [18]. In making this point, the inquiry problematizes the uncritical assumption that all traditional education theories especially those from peripheral cultures are necessarily irrelevant to contemporary language education. It is our language teachers' professional commitment to delve into how certain practices which learners from non-Anglophone background have inherited from their own cultures are appreciated and made good use of.

\section{Fund}

This paper is supported by the Key Research Project of Southwest University of Political Science and Law in 2017, the United Front Research Project of Southwest University of Political Science and Law in 2017 (2017XZTZ-07) and Scientific Research of Higher Education of Chongqing, China.

\section{References}

[1] Kim, H.-K. (2003) Critical Thinking, Learning and Confucius: A Positive Assessment. Journal of Philosophy of Education, 37, 71-87. https://doi.org/10.1111/1467-9752.3701005

[2] Freire, P. (1972) Pedagogy of the Oppressed. Herder and Herder, New York.

[3] Dewey, J. (1903) Democracy in Education. The University of Chicago Press, Chicago.

[4] Thompson, I. (1987) Memory in Language Learning. In: Wenden, A. and Rubin, J., Eds., Learner Strategies in Language Learning, Prentice Hall, New York, 43-56.

[5] Freire, P. (1975) The Pedagogy of Liberation, In: Rich, J.M., Ed., Innovations in Education: Reformers and their Critics, Allyn \& Bacon, Boston.

[6] Freire, P. (1993) The Banking Concept of Education. In: Bartholomae, A. and Petrosky, B., Eds., Ways of Reading, St. Martin, New York.

[7] Freire, P. (1976) Education: The Practice of Freedom. Writers and Readers Co-Operative, London.

[8] Taylor, P.V. (1993) The Text of Paulo Freire. Open University Press, Buckingham.

[9] Reimer, E. (1970) Does the Shoe Fit? A Background Piece on the "Silent Majority". 
America, 23, 69-70.

[10] Harman, D. (1971) Methodology for Revolution. Saturday Review.

[11] Wirth, A.G. (1966) John Dewey as Educator: His Design for Work in Education (1894-1904). John Wiley \& Sons, Inc., New York.

[12] Maley, A. (1983) Xanadu- “A Miracle of Rare Device”: The Teaching of English in China. Language Learning and Communication, 2, 1-13.

[13] Graham, A.C. (1989) Disputers of the Tao: Philosophical Argument in Ancient China. Open Court, La Salle.

[14] Confucius (2000) The Analects trans. by Dawson R. Oxford University Press, Oxford.

[15] Chang, C. (1954) Reason and Intuition in Chinese Philosophy. Philosophy East and West, 4, 99-112. https://doi.org/10.2307/1397521

[16] Confucius (2006) Aphorisms from LIJI. Trans. by Sun ChangKun, QiLu Press, Ji'nan.

[17] Confucius (2006) Aphorisms from LUNYU. Trans. by Li Hui et al., QiLu Press, Ji'nan.

[18] Yao, X.-Z. (2000) An Introduction to Confucianism. Cambridge University Press, Cambridge. https://doi.org/10.1017/CBO9780511800887

[19] Sampson, G.P. (1984) Exporting Language Teaching Methods from Canada to China. TESL Canadian Journal, 1, 19-31. https://doi.org/10.18806/tesl.v1i1.421

[20] Lee, W.O. (1996) The Culture Context for Chinese Learners: Conceptions of Learning in the Confucian Tradition. In: Watkins, D.A. and Biggs, J.B., Eds., The Chinese Learner. Cultural, Psychological and Contextual Influences, The Comparative Education Research Centre, Faculty of Education, University of Hong Kong, Hong Kong, 25-41.

Submit or recommend next manuscript to SCIRP and we will provide best service for you:

Accepting pre-submission inquiries through Email, Facebook, LinkedIn, Twitter, etc. A wide selection of journals (inclusive of 9 subjects, more than 200 journals) Providing 24-hour high-quality service User-friendly online submission system Fair and swift peer-review system Efficient typesetting and proofreading procedure Display of the result of downloads and visits, as well as the number of cited articles Maximum dissemination of your research work

Submit your manuscript at: http://papersubmission.scirp.org/

Or contact jss@scirp.org 